\title{
Cosmetic tail docking: an overview of abuse and report of an interesting case
}

\author{
Oghenemega David Eyarefe ${ }^{*}$ and Cecilia O. Oguntoye
}

\begin{abstract}
Background: This paper presents an overview of the global controversies surrounding cosmetic tail docking in puppies, some observed inconsistent practices among dog breeders and Veterinarians in West Africa, and the need for the African Veterinary Profession to take a decisive position on the cosmetic docking procedure.

Case presentation: An interesting report of observed complications associated with cosmetic tail docking in a 3 week old male Boerboel is reported alongside the management of the ensuing complications.

Conclusion: This paper highlights the still prevalent practice of cosmetic tail docking and seeks to enlighten clinicians towards stemming its abuse in Africa.
\end{abstract}

Keywords: Dog, Tail docking, Abuse, Rubber rings, Animal welfare

\section{Background}

Tail docking is the amputation of a part or all of an animal's tail [1]. In puppies, it is usually performed between day three to five of life or at 3 months under general anaesthesia by surgical amputation with a scalpel [2]. Some breeders, however, perform tail docking without anaesthesia by the application of tight rubber rings around the tail which serves to occlude vessels caudal to the rubber ring, resulting in ischemic necrosis and sloughing of the tail $[1,3]$. Tail docking in animals, especially dogs, remains a controversial subject among veterinarians, animal breeders, pet owners and animal welfare groups in many countries of Europe and the United States of America (USA) $[1,4,5]$. The procedure has been banned in the United Kingdom with exceptional provision made for therapeutic and prophylactic tail docking in certified working dogs [6]. Cosmetic tail docking is gradually becoming an issue in Africa with South Africa leading in the ban against the procedure [7] while other African countries are yet to have a legislative position on the procedure.

Tail docking in many dog breeds is an established custom believed to have been introduced some 2000 years ago [1]. In recent times, dogs' tails are supposedly docked to conform to breed standards, prevent tail injuries, and to potentially reduce the accumulation of fecal materials

\footnotetext{
* Correspondence: odeyarefe@gmail.com

Department of Veterinary Surgery and Reproduction, Faculty of Veterinary Medicine, University of Ibadan, Ibadan, Nigeria
}

around the tail area of dogs with excessive coat $[1,8]$. Docking dogs to prevent tail injuries has, however, been controverted by many recent studies $[9,10]$. In a study conducted in Great Britain, to assess the risk of tail injury and associated risk factors, as well as, to allow objective assessment of the frequency of tail injury and risk factors associated with them [9]; the overall risk of tail injuries was low. The weighted risk was $0.23 \%$ per year, with working-dogs being $0.29 \%$ and non-working dogs $0.19 \%$ [9]. The study concluded that, although docking appears to be protective against injury, over 500 dogs would need to be docked in order to prevent one tail injury [9]. In another recent study to assess the nature of canine tail injury in New Zealand [10], it was concluded that tail injuries are rarely observed in Veterinary clinics, and docking a risk factor in traditionally docked breeds [10]. Tail docking is associated with severe acute pain which often causes behavioural distress in puppies [11] especially when performed without anaesthesia or analgesia, especially as with rubber ring. Chronic pain arising from tail stump infections and neuromas have also been reported [12-14], and elucidated with pain studies in other species [15]. Chronic health challenges such as faecal incontinence, atrophy of pelvic muscles [5], frequent tail damage [9, 16, 17], impaired locomotory and communication defects have also been reported and confirmed through previous studies $[4,5]$. These complications, and lack of dog's benefit from the procedure have raised strong oppositions 
from Veterinary associations and animal welfare groups $[3,18,19]$ resulting in the ban of non-therapeutic animal docking in many European countries, Australia and South Africa [3, 7, 20-23].

The current influx of traditionally docked breeds into major countries of Africa including Nigeria has heightened the non-therapeutic dog tail docking practice [7], with non-compliance to docking time for puppies [7], abuse of the rubber band docking method, indiscriminate docking of dog breeds and non-cognisance of the required number of residual coccygeal vertebrae in line with breed standards (Authors' unpublished observations). These have resulted in an upsurge of post-docking complications and animal suffering. This paper, which is the first of its kind from Nigeria, reports one of such tail docking abuses, and the ensuing complications as evidence of cruelty to companion animal species, and a call for a strong legislation towards the ban of cosmetic tail docking in all African Countries .

\section{Case presentation}

A 3 week and 2 day old male Boerboel was presented at the Surgery Unit of the Veterinary Teaching Hospital of the University of Ibadan, Ibadan, Nigeria, with a severely swollen, gangrenous tail which, according to the owner, occurred following an attempt to amputate the tail with a rubber ring tied tightly on the tail two weeks previously (Figs. 1 and 2). This puppy's tail did not slough off; though his six other litter mates did about 7 days following the placement of the band. The puppy was severely distressed with pain at presentation; evidenced by continual vocalisation. Owner also complained of loss of appetite and un-thriftiness among its litter mates.

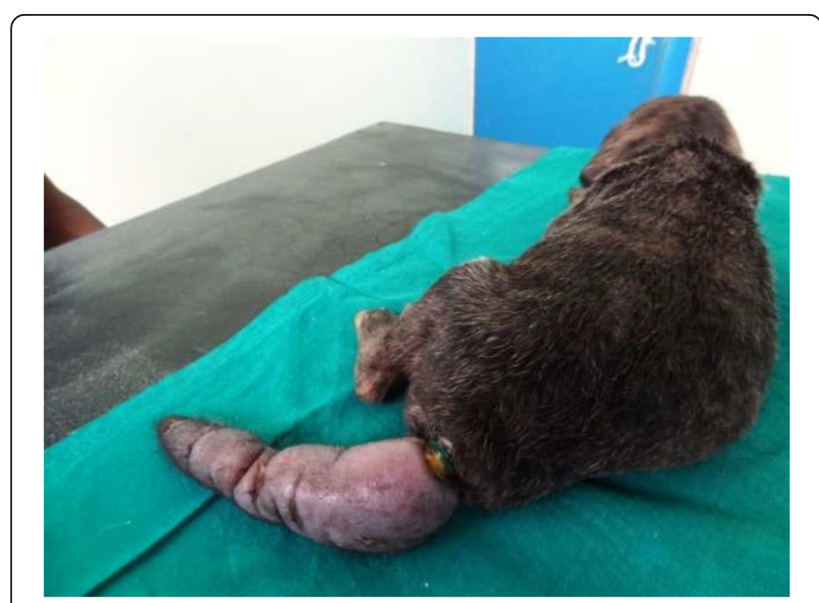

Fig. 1 Initial presentation: a swollen, ischaemic, necrotic tail. Legend: The initial picture of the tail is shown at the point of presentation. At this point, the tail has failed to slough off after 2 weeks of rubber ring application. The tail is swollen and necrotic and painful to the touch. When the pup attempts to move, it does so with the tail being dragged on the floor behind it

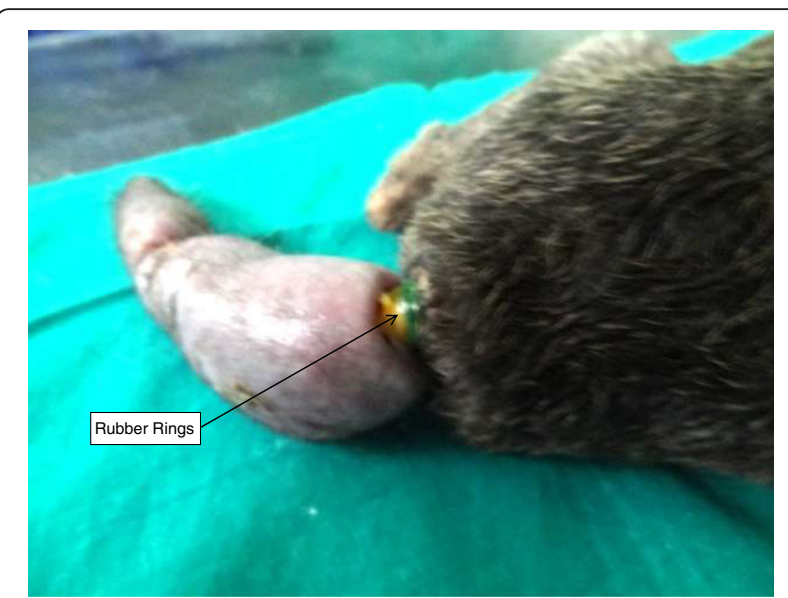

Fig. 2 Puppy's tail with rubber ring attachment. Legend: The point of application of the rubber rings is highlighted, just at the root of the tail where it joins to the hip. Several rings of rubber bands are clearly visible

\section{Physical examination}

The puppy weighed $2 \mathrm{~kg}$. Its rectal temperature was normal $\left(37.6{ }^{\circ} \mathrm{C}\right)$ but other physiological parameters were slightly elevated although within normal range. The point of rubber band application was septic (Fig. 2), and the rubber rings were on the second coccygeal vertebrae.

\section{Surgical treatment}

Following 2 intranasal drops of Ketamine hydrochloride $(0.1 \mathrm{mg} / 100 \mathrm{~g})$ which sedated the patient, as previously described [2], lumbosacral epidural nerve block was done with $2 \%$ lignocaine (Glocain, Vital Care Limited, India) at a dose rate of $1 \mathrm{ml} / 6 \mathrm{~kg}$ body weight [24]. Docking was at the root of the tail and incision closed with cruciate suture pattern using size 1-0 nylon sutures (Fig. 3). Healing was uneventful, sutures were removed (Fig. 4) and puppy grew rapidly to equal litter mates' weight within 2 weeks.

\section{Discussion}

Cosmetic tail docking remains controversial for acute and chronic pain associated with the procedure [3]. This is more severe in puppies due to incomplete myelination of their nerve sheet which make them more sensitive to pain than adults [13]. As previously reported [3], the tail is a complex anatomical structure comprising of ligament, muscles, and tendon, well innervated and vascularised. It is absolutely cruel when the pain threshold from the time of fixing the rubber ring is imagined [11], as each puppy struggles through the period of tightened rubber band leading to ischaemic necrosis and sloughing of the tail. Although rubber ring method is conventional for prophylactic tail docking in lambs; aside gas heated hot knife and sharp knife [25], the method is also reportedly associated 


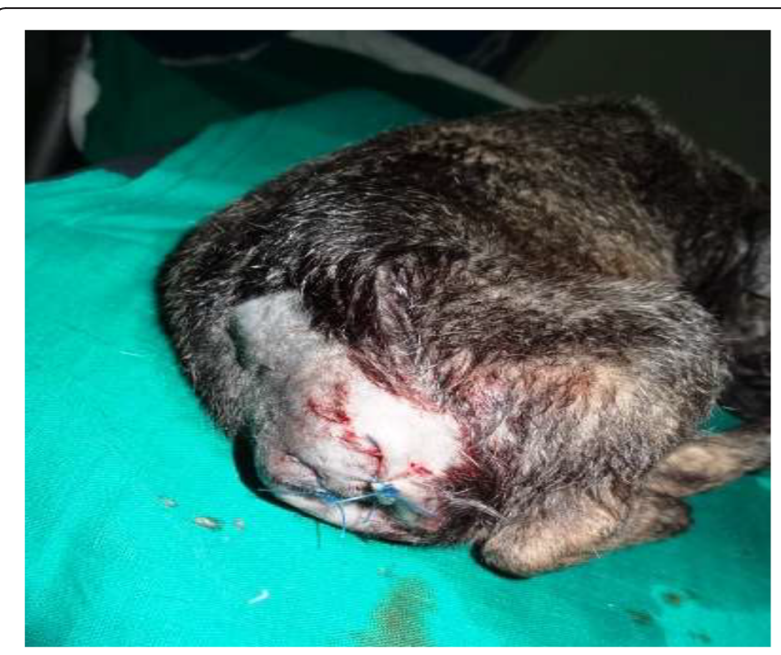

Fig. 3 Tail stump after surgical therapeutic docking. Legend: After therapeutic excision of the affected tail, the stump is pictured

with intense pain [26] and high cortisol response [27, 28], abnormal postural display [29] irrespective of docking age [30]. There is also a prolonged average period of 28 days before the tail sloughs off [31]. This may explain why the rubber ring method though tolerated in lambs may not be suitable for prophylactic tail docking in dogs. Besides, a more intense pain and sloughing prolongation have been reported when docking rings are placed on the vertebrae instead of in-between vertebrae [32]; a position which may be difficult to ascertain by un-trained persons. The phylogenic differences between the ovine and the canine species (tail muscle size, length, rate of coccygeal osteogenicity) may also explain while the rubber ring method may be less suitable in canine species [33]. Attempt at docking this puppy was made at the ninth day of life, instead of

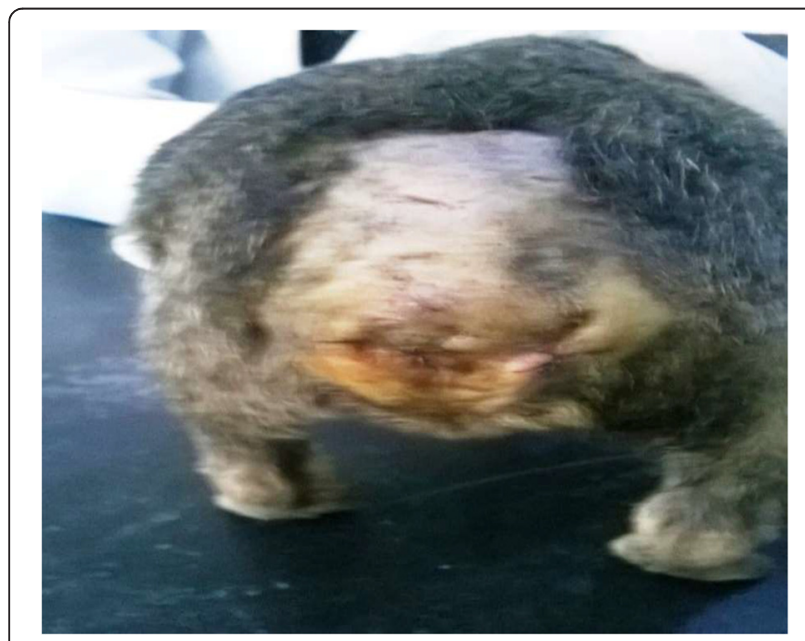

Fig. 4 Tail region after a removal of sutures. Legend: A picture is shown after the sutures are removed. The stump is healing nicely as expected, with uneventful cosmetic appearance between day three to five as contained in literature [2]. The development of coccygeal cartilage to bone may have also contributed to the docking failure. Besides, docking of this puppy beyond the time suggested in literature shows the desperation of breeders to dock their dogs' tail without consideration of inherent complications associated with their wrong actions. This is more pronounced in poor resource setting of many African countries where money is a prime factor, and docking is done to enhance sales of puppies [7]. The use of intranasal sedation/ anaesthesia with ketamine hydrochloride was reported in literature for puppy docking [2]. The process enhanced chemical restraint of puppy and eased administration of epidural nerve block to provide intra-operative and postoperative analgesia [34].

\section{Conclusions}

Cosmetic tail docking is cruel to puppies, and other species, especially when done without anaesthesia. Veterinary and Animal Welfare Associations in African countries should therefore move a legislative process that could lead to a ban of the procedure.

\section{Competing interests}

The authors declare that they have no competing interests.

\section{Authors' contributions}

ODE and COO handled the case when first presented to the Veterinary Hospital, University of Ibadan. ODE handled the surgical excision of the necrotic tail; COO was the anaesthesiologist. ODE conceived this report and helped to draft the manuscript. Both authors read and approved the final manuscript.

\section{Acknowledgement}

The authors wish to acknowledge the contributions of Mrs Adekunle and Mrs Ogundiran to the management and quick recovery of this patient as well as interaction with the owner for vital information about the patient. Also, they acknowledge Dr. Afolabi who helped with the manuscript editing and typesetting.

Received: 13 July 2015 Accepted: 24 February 2016

Published online: 29 February 2016

\section{References}

1. Bennett PC, Perini E. Tail docking in dogs: a review of the issues. Aust Vet J. 2003;81(4):208-18.

2. Hedlund CS. Surgery of the integumentary system. In: Fossum TW, editor. Small Animal Surgery. 3rd ed. St. Louis (MO): Mosby; 2007. p. 246-50.

3. Lefebvre D, Lips D, Giffroy JM. The European Convention for the protection of pet animals and tail docking in dogs. Rev Sci tech Off Int Epiz. 2007;26(3): 619-28.

4. Morton D. Docking of dogs: practical and ethical aspects. Vet Rec. 1992; 131(14):301-6.

5. Wansbrough RK. Cosmetic Tail docking in dogs. Aust Vet J. 1996;74(1):59-63.

6. Animal Welfare Act 2006 Chapter 45 p.6. www.legislation.gov.uk/ukpga_ 20060045_en.pdf. Accessed 11 September 2015

7. Akinrinmade JF. Tail Docking: Evaluation of Current practices and Ethical aspects in Southwest Nigeria. J Vet Med Anim Health. 2014;6(1):18-24.

8. American Veterinary Medical Association: Literature Review on the Welfare Implications of Tail Docking- Dogs. 2013. https://www.avma.org/KB/ Resources/LiteratureReviews/Pages/Welfare-Implications-of-Tail-DockingDogs-Backgrounder.aspx. Accessed 19 September 2015

9. Diesel G, Pfeiffer D, Crispin S, Brodbelt D. Risk factors for tail injuries in Great Britain. Vet Rec. 2010;166:812-7. 
10. Wells A, Hill KE, Stafford K, Wink WD. The tail injury justification of canine tail docking: Prevalence, causes, treatments and risk factors of canine tail injuries in New-Zealand. Institute of Veterinary Animal and Biochemical Sciences, Massey University, New-Zealand. (2011). http://tail-waggingcampaign.org.nz/documents/Massey\%20\%University\%20reference\&20material. pdf. Accessed 19 September, 2015

11. Noonan GR, Rand J, Blackshaw J. Behavioural observerations of puppies undergoing tail docking. Appl Anim Behav Sci. 1996;49:335-42.

12. Gross TL, Carr SH. Amputation neuroma of docked tails in dogs. Vet Pathol. 1990;27:61-2.

13. Fitzgerald $\mathrm{M}$. The neurobiology of fetal and neonatal pain. In: Wall PD, Melzack R, editors. A Textbook of Pain. 3rd ed. Edinburgh: Churchill Livingstone; 1994. p. 153-63.

14. French NP, Morgan KL. Neuromata in docked lambs' tails. Res Vet Sci. 1992; 52(3):389-90.

15. Moloney V, Kent JE. Assessment of acute pain in farm animals using behavioural and physiological measurements. J Anim Sci. 1997;75:266-72.

16. Darke PG, Thrushfield MV, Aitken CG. Association between tail injuries and docking in dogs. Vet Rec. 1985;116(15):409.

17. Why the tail docking of dogs should be prohibited - one kind. https:/www. onekind.org/uploads/publications/tail-docking-dogs.pdf. Accessed 26 February 2016.

18. AWVT. Animal Welfare Veterinary Team: A review of the scientific aspects and veterinary opinions relating to tail docking in dogs. Department for Environment, Food and Rural Affairs. 2000.

19. Canadian Veterinary Medical Association Cosmetic alteration- Position statement 2014;1-15. http://www.canadianveterinarians.net/default.aspx. Assessed 26 February 2016

20. Warman J. The Proposed Bill to Ban Tail Docking. 2004; http://www.nzkc org.nz/taildocking.html Accessed 26 June 2015.

21. Delafenetre D. Landseer's Ethics: The campaign to end "Cosmetic Surgery" on dogs in Australia. In: Carrol Gigliotti, editor. Leonardo's choice: genetic technologies and animals, New York: Springer; 2009 p. 193-214.

22. American veterinary Medical association (AVMA). Welfare Implications of Tail Docking- Dogs Literature Review. http://www.avma.org/KB/Resources/ LiteratureReviews/Pages/081215c.aspx. 2013. Accessed 26 February 2016.

23. Crook A. Cometic surgery in Horth America and Latin America: Proceeding of World Small Animal Veterinary Association. 2001:54-5

24. Skarda RT, Tranquilli WJ. Local and regional Anaesthetic and Analgesic Techniques in dogs. In: Tranquilli WJ, Thurmon JC, Kurt A, editors. Lumb \& Jones Veterinary Anaesthesia and Analgesia, Fourth Edition. Oxford: Grimm Blackwell Publishing Limited; 2007. p. 576.

25. Lewis GS. Tail length at docking and weaning of lambs. Sheep and goat research journal. 2013;28:6-9.

26. Lomax S, Dickson H, Shiell M, Windsor PA. Topical anaesthesia alleviates short-term pain of castration and tail docking in lambs. Aust Vet J. 2010;88:67-74.

27. Mellor DJ, Stafford KJ. Review of acute castration and/or tailing distress and its alleviation in lambs. NZ Vet J. 2000;48:33-43.

28. Luther J. Causes, prevention and treatment of rectal prolapse in sheep. NDSU Extension Service North Dakota State University Fargo, North Dakota 58105 September 2008. AS-1388.

29. Grant C. Behavioural responses of lambs to common painful husbandry procedures. Appl Animal Behaviour Science. 2004;87:255.

30. Farm Animal Welfare Council Report on the Implications of Castration and Tail Docking for the Welfare of Lambs, June 2008, Farm Animal Welfare Council, London at: http://www.fawc.org.uk/reports.htm Accessed 19 September 2015

31. Goodwin J, Murphy T and Jacobson R. A path to resolution regarding the show lamb taildocking controversy. J Extension. 2007;45: Article 4FEA8.

32. Morris MC. Ethical issues associated with sheep fly strike research, prevention, and control. J Ag Envir Ethics. 2000;13:205-17.

33. Baker RJ, Bradley RD. Speciation in mammals and the genetic species concept. J Mammal. 2006;87(4):643-62.

34. McKelvey D, Hollingshead KW. Veterinary Anaesthesia and Analgesia. St. Louis, Missouri: Mosby Inc; 2003. p. 294.

\section{Submit your next manuscript to BioMed Central and we will help you at every step:}

- We accept pre-submission inquiries

- Our selector tool helps you to find the most relevant journal

- We provide round the clock customer support

- Convenient online submission

- Thorough peer review

- Inclusion in PubMed and all major indexing services

- Maximum visibility for your research

Submit your manuscript at www.biomedcentral.com/submit
Biomed Central 